\title{
LA GRÁFICA POLÍTICA Y LOS MARCOS DE ACCIÓN COLECTIVA en San Cristóbal de Las Casas, Chiapas (2010-2013)
}

\author{
The Political Images and a Collective-Action Framework \\ in San Cristóbal de Las Casas, Chiapas (2010-2013)
}

\author{
Carlos de Jesús Gómez-Abarca
}

Resumen: El objetivo de este artículo es interpretar la gráfica política realizada en San Cristóbal de Las Casas, Chiapas, integrada por composiciones que generalmente incluyen texto e imágenes. Se realizó, inicialmente, un análisis elemental de tipo semiótico visual a un registro fotográfico (2010-2013) de 63 producciones visuales, el cual fue complementado, posteriormente, con una interpretación desde la perspectiva de los marcos de acción colectiva. Se concluye que estas intervenciones, además de ser un vehículo de expresión política, constituyen marcos interpretativos que orientan las acciones colectivas de los diferentes actores políticos que confluyen en la ciudad.

Palabras clave: participación juvenil, participación política, movimientos sociales, comunicación política, arte urbano.

Abstract: The objective of this article is to interpret political imagery in San Cristóbal de Las Casas, Chiapas, i.e., activists' artistic expressions that generally include texts and pictures. I prepared an elementary visual semiotic analysis of a photographic record (20102013) that includes 63 visual productions, using an analytical framework approach. I conclude that these expressions, besides being a vehicle for political statement, constitute interpretative frameworks that guide the collective actions of various political actors and are in themselves a form of collective action.

Keywords: youth participation, political participation, social movements, political communication, urban art.

Carlos de Jesús Gómez Abarca. Sociólogo. Candidato a doctor en Ciencias Sociales y Humanísticas por el Centro de Estudios Superiores de México y Centroamérica de la Universidad de Ciencias y Artes de Chiapas, México. Investigador en el Observatorio de las Democracias: Sur de México y Centroamérica de la Universidad de Ciencias y Artes de Chiapas, México. Temas de especialización: juventud, participación, activismos juveniles, acción colectiva y movimientos sociales. Correo electrónico: jesus.gomezabarca@gmail.com.

Enviado a dictamen: 24 de enero de 2017.

Aprobación: 17 de octubre de 2017.

Revisiones: 2. 
L as inscripciones visuales callejeras han ganado presencia en diferentes ciudades a partir de la segunda mitad del siglo XX. Éstas son realizadas en un sinnúmero de formatos y con una diversidad de contenidos en los muros y otras plataformas del mobiliario urbano, coexistiendo y disputándose el paisaje visual con otras intervenciones realizadas por las empresas locales, nacionales y trasnacionales, y por las instituciones del Estado.

En este artículo realizo un análisis de intervenciones que expresan posicionamientos políticos. 'Se tratarán en específico aquellas que reciben el nombre de plantillas, esténciles o estarcidos por la técnica utilizada para su elaboración. El principal referente empírico de este análisis de tipo semiótico visual consta de 63 producciones mixtas capturadas en la ciudad de San Cristóbal de Las Casas, Chiapas, entre 2010 y 2013. ${ }^{2}$

La hipótesis que subyace en este análisis es que, además de constituir un canal de expresión política, los esténciles o estarcidos ${ }^{3}$ que se encuentran en esta ciudad son susceptibles de ser decodificados e interpretados como marcos simbólicos que orientan diferentes acciones colectivas.

En tanto marcos simbólicos, es posible observar en estas expresiones la problematización que efectúan diferentes grupos en torno a situaciones que perjudican a sus integrantes personal o colectivamente. Los marcos de acción colectiva, teoría dada a conocer en el campo de las teorías de los movimientos sociales por Robert Benford y David Snow y otros autores (Snow et al., 1986; Benford y Snow 1997, 2000), sugiere que, como producto de los procesos de "encuadre" (framing), se pueden reconocer tres tipos de marcos que se tratarán en el texto más adelante: los de diagnóstico, los de pronóstico y los motivacionales.

El trabajo está organizado en tres partes principales más un apartado de conclusiones. En un primer momento se plantea la pertinencia de realizar un análisis de las intervenciones visuales contemporáneas, particularmente de aquellas que tienen contenido político; en un segundo momento se recuperan postulados básicos de la perspectiva de marcos de acción colectiva como una vía para el análisis de los registros empíricos; posteriormente se analizan los registros visuales obtenidos durante el trabajo de campo $y$, finalmente, a manera de conclusiones, se recapitulan los argumentos centrales que permiten confirmar las premisas planteadas y la hipótesis de trabajo.

\section{Sobre las intervenciones urbanas y su estudio}

En México se han estudiado a profundidad, al menos, tres modalidades de intervenciones urbanas: 1) los códigos lingüísticos que se han desarrollado con fines territoriales entre bandas de barrios marginales a partir de la década de los ochenta, como es el caso del "cholismo" en la frontera norte de México y de los chavos banda en la Ciudad de México; 2) el graffiti hip-hop, surgido con el movimiento de taggers que inició en diferentes ciudades estadounidenses, y fue desarrollado en el seno de la cultura del gueto por grupos latinoamericanos y afrodescendientes; y 3) la gráfica política utilizada por movimientos sociales y populares como parte de sus repertorios de acción o como acciones de militancia comunicacional o cultural (Valenzuela, 1997; Marcial, 2012).

Mientras las primeras dos modalidades han sido temas de estudio relevantes en las ciencias sociales en México, particularmente desde los estudios de juventud, la tercera modalidad, la gráfica política, ha recibido menor atención. Conviene señalar, sin embargo, que el desarrollo de estas técnicas no se da de manera aislada. En San Cristóbal de Las Casas, por ejemplo, el esténcil político se ha desarrollado a la par de otras intervenciones, denominadas genéricamente como arte urbano, arte callejero o street art, ${ }^{4}$ graffiti $^{5}$ o posgraffiti. ${ }^{6}$

Los sentidos y los usos que se le asignan al esténcil, sin embargo, permiten trazar algunas distinciones. En San Cristóbal existe un relativo acuerdo en que los esténciles pueden llegar a ser complementos en la elaboración de un graffiti, mas no pueden ser considerados por sí mismos como graffitis y, por ende, no todos los que utilizan un aerosol pueden reconocerse como graffiteros - en el marco de la cultura hiphop-. Además de estos usos, no debe olvidarse que los esténciles son utilizados para la realización de 
propaganda política o con fines comerciales, de ahí la necesidad de acotar el análisis a aquellos con contenido político.

No es posible asignar una fecha de origen a las intervenciones visuales con contenido político plasmadas con el uso de aerosol, plantillas, afiches y otros formatos. Sin embargo, desde finales de los años sesenta, fuertemente impulsadas por los estudiantes movilizados en diferentes partes del mundo, comenzaron a proliferar las "pintas" o consignas políticas, que generalmente incluían sólo texto.

Históricamente la palabra, expresada en sus múltiples modalidades, ha sido un canal privilegiado para la comunicación de los militantes. "Tú ni siquiera mereces un graffiti" es el mensaje sustraído de una pinta realizada en la década de los ochenta en Santiago de Chile. A pesar de los múltiples significados que la pinta podría contener, en el contexto de dictadura, el contenido de esta escritura alternativa se restringe a la enunciación del hartazgo por las prohibiciones y la violencia del régimen militar encabezado por Pinochet.'

A la centralidad de la palabra se ha sumado, en las últimas décadas, la imagen como una potente plataforma de transmisión de contenidos (Benedicto, 1995). ${ }^{8}$ En diferentes medios como los libros, los fanzines, ${ }^{9}$ las pancartas, las consignas, los blogs, las redes sociales cibernéticas y las revistas impresas y electrónicas se recurre a la ilustración para complementar y fortalecer los mensajes políticos, satirizando o caricaturizando algún personaje político, por ejemplo.

En San Cristóbal de Las Casas se comenzaron a observar pintas con sentido político a finales de la década de los setenta y comienzos de los ochenta. Posteriormente, con el surgimiento del movimiento armado del Ejército Zapatista de Liberación Nacional y el ulterior movimiento zapatista en la década de los noventa, se hicieron comunes las expresiones de apoyo a este movimiento y las denuncias sobre determinadas acciones políticas realizadas por diferentes actores, como la detención de presos políticos. En esta misma década comenzaron a observarse también graffitis que años más tarde se vincularon a la cultura hip-hop (Gómez-Abarca, 2014).
Estas expresiones visuales han sido correlato de transformaciones ocurridas en la ciudad. En el último cuarto del siglo XX, algunos fenómenos sociales que han influido en tales cambios son: las diferentes oleadas masivas de migración forzada de indígenas tsotsiles que se mudaron a la ciudad por motivos político-religiosos en los setenta, y la crisis en el campo durante los ochenta (Rus, 2009 y 2012); el asentamiento de organizaciones civiles desde la década de los ochenta en la ciudad, como centro estratégico para sus actividades en la región (González, 2007); el levantamiento del movimiento zapatista en la década de los noventa y los impactos que produjo en diferentes escalas (Viqueira, 2002); y el impulso al sector turismo, promovido por la Secretaría de Turismo, principalmente desde el año 2001.

En la actualidad, la gráfica política se observa en esténciles y afiches que contienen temáticas diversas y que, en cuanto a composición, se caracterizan básicamente por contener imágenes, texto o ambos, y por estar realizados en un solo color y en "pequeño formato" - en la mayoría de los casos no superan los cincuenta centímetros cuadrados-. Se pueden observar estas intervenciones en diferentes espacios de la ciudad, aunque se concentran en las calles que rodean el primer cuadro de la misma, lo que no es casual porque estos entornos constituyen el centro de múltiples protestas (ver ilustración l).

En la ciudad, las inscripciones urbanas analizadas han sido realizadas por diferentes colectivos y organizaciones sociales, muchas veces en eventos de protesta. Coincido con Morales Vargas (2013) en que estas obras expresan posturas políticas y disidencias sociales, aunque también son acciones colectivas en sí mismas, lo que implica reconocer que no sólo constituyen un producto, sino que son parte de procesos más amplios de protesta y movimientos sociales.

Las producciones de gráfica política, como otras intervenciones callejeras, son realizadas, generalmente, de manera ilegal y clandestina, tienen una presencia efímera y son depositarias de un fuerte sentido transgresor. Por ende, representan un agravio contra la propiedad privada y atentan contra las disposiciones oficiales sobre los espacios urbanos, lo que es 
interpretado por muchas personas, particularmente por los afectados, como actos vandálicos, percepción que es fortalecida por los medios de comunicación.

La cualidad transgresora de la gráfica política coloca a ésta en una disputa por la redefinición de los espacios urbanos., de tal manera que el estudio de estas intervenciones abre la posibilidad de problematizar otros procesos que se llevan a cabo en la ciudad, tales como: las redefiniciones del espacio urbano bajo una tendencia privatizadora; los conflictos que se dan en el espacio público entre diferentes grupos; las políticas que rigen la organización del espacio y los usos destinados para éste; la organización socioespacial de la ciudad; la configuración estética de la ciudad; la inclusión y exclusión de los habitantes, y las prácticas toleradas y las proscritas (Rodríguez, 2016: 23).

Lo anterior conduce a problematizar el paisaje iconográfico contemporáneo, definido menos por la apertura y multiplicación de las posibilidades para ver el mundo, y más por el uso de los medios visuales que procuran el "sometimiento de la mirada", manipulando los sentidos con fines comerciales. Para Pablo Lazo, el resultado es una "iconografía de la vaciedad", comprometida con el mercado y el uso publicitario, pero desarraigada de los usos y contenidos sociales, desconectada de sentido, carente de pasado y memoria (Lazo, 2007). La gráfica política se sitúa a contrapelo de esta tendencia reduccionista y comercial.

El estudio de la gráfica política, por tanto, da pauta para reflexionar en torno al vínculo entre información, imagen y poder (Benedicto, 1995; Sartori 1998). La importancia que cobran hoy en día los asesores de imagen en la política partidista (ver ilustración 2) ${ }^{10}$ y el uso de los medios masivos de comunicación en los procesos de criminalización de la protesta a través de narrativas audiovisuales ejemplifican la instrumentalización de la imagen por diferentes actores políticos. ${ }^{11}$ A estas prácticas comunicativas se suman la vigilancia con cámaras de seguridad y el espionaje electrónico, una especie de "panóptico contemporáneo" (Lizarazo, 2007: 12).

Ante el uso político y hegemónico de los universos iconográficos contemporáneos, resulta fundamental cuestionar el sentido ético, estético y político con que las intervenciones han sido realizadas y los contextos en que se encuentran inmersas. De esta forma, es posible reconocer que algunos "grupos culturales son capaces de actos interpretativos, con cierto margen de libertad" (Lazo, 2007: 57), al expresar disidencias creativas en el ordenamiento visual, lingüístico y socioespacial, y al interpelar con ello a los transeúntes. En otras palabras, las intervenciones visuales se presentan como textos organizados, "revelándonos un mundo, una mirada, una verdad, lo inefable" (Lizarazo, 2007: 12).

Las intervenciones visuales realizadas con sentido crítico pueden leerse, en este sentido, como prácticas contrahegemónicas toda vez que expresan los conflictos que subyacen a numerosas movilizaciones sociales, algunas de larga data. Al mismo tiempo, se hace patente la forma en que la cultura y el arte se han incorporado a los repertorios de acciones colectivas contemporáneas y han promovido la apropiación de los espacios públicos, la búsqueda de concientización social y la reelaboración de una memoria.

El reconocimiento de que muchas de estas intervenciones visuales forman parte de tramas más amplias como los movimientos sociales permite poner en dimensión su estudio. La gráfica política puede entenderse como un producto o vehículo comunicativo, pero también como parte de un complejo sistema de acción colectiva en el que intervienen actores, objetivos, sentidos, recursos, identidades, expectativas y limitaciones múltiples (Melucci, 1999: 12).

\section{Gráfica política y marcos de acción colectiva}

El análisis de las producciones de gráfica política se trata en este artículo desde una perspectiva cultural. El estudio del vínculo entre cultura y política no es analíticamente novedoso, pero la cultura se ha abordado de manera marginal. En los estudios de movimientos sociales, por ejemplo, ésta ha sido considerada desde las nociones de ideología y, con mayor énfasis, en las teorías de los nuevos movimientos sociales. No fue hasta la segunda mitad del siglo XX cuando ganó centralidad en el estudio de los movimientos sociales (Jasper, 2014; Ulrich, Daphi y Baumgarten, 2014). 
La teoría de los encuadres (frame anlalysis), impulsada principalmente por Benford y Snow (Snow et al., 1986; Benford y Snow 1997, 2000), y la incorporación de variables culturales en diferentes modelos teóricos "estructuralistas" son ejemplos de la importancia que ha cobrado el estudio de la cultura en los últimos años. Estos autores parten del supuesto de que los problemas no existen de manera objetiva, sino que los actores de cada movimiento son agentes que participan activamente en la problematización de una situación mediante la construcción de significados. Este proceso ha recibido el nombre de "encuadre" (framing), mientras que los productos resultantes de este encuadre son denominados "marcos de acción colectiva" (Johnston, 2005; Ulrich, Daphi y Baumgarten, 2014).

Los marcos de acción colectiva pueden entenderse como elaboraciones simbólicas, negociadas entre los adherentes de un movimiento, sobre el entendimiento compartido de una condición o situación problemática. De éstas se deriva la asignación de responsabilidades y la proyección de acciones para transformar dicha problemática. Aunque en la práctica las personas no suelen seguir una lógica lineal en la construcción de marcos de acción, analíticamente es posible hablar de tres partes constitutivas que son el resultado de este proceso: el marco de diagnóstico, el marco de pronóstico y el marco motivacional (Benford y Snow 1997, 2000).

El marco de diagnóstico refiere a la forma en que un conjunto de personas define una realidad como problemática (Benford y Snow, 2000), la cual anteriormente pudo haber pasado desapercibida, había sido naturalizada o se atribuía a factores naturales o a responsabilidades individuales (Della Porta y Diani, 2006: 74). La definición del problema no está exenta de polémica debido a que, por lo común, algunos actores procuran imponer sobre otros su definición o diagnóstico de la problemática; por este motivo, los actores que componen los movimientos sociales buscan argumentar o legitimar sus propias lecturas de la situación.

Un paso fundamental en la construcción de los esquemas de interpretación es la identificación del agravio y de los responsables de la situación en que se encuentra la población agraviada, lo que por lo común está atravesado por un fuerte componente moral que se puede caracterizar para fines analíticos por, al menos, dos partes. La primera, como un conjunto de principios de justicia que orientan las acciones de manera explícita, y, la segunda, como principios que orientan las acciones la mayor parte del tiempo y se presentan en forma de intuiciones que son sentidas, en vez de ser explícitamente formuladas (Jasper, 2014: 26).

En esta línea argumentativa, Jasper plantea la noción de choques morales, entendidos como eventos o como información tan perturbadora, que hace que las personas que no se dedican de tiempo completo a la política sean reclutadas con mayor facilidad, lo que da un fuerte impulso al movimiento (Jasper, 2014: 93). Muchas veces la acción política es resultado de la actitud de desesperanza. Posteriormente, los activistas intentan generar transformaciones morales por medio de propia propaganda, por ejemplo, a través de imágenes alarmantes o historias de crueldad y opresión (Jasper, 2014: 125).

En el plano internacional, la indignación de amplios sectores de la población que impulsó su movilización hacia las calles es un ejemplo de los choques morales que anteceden a la acción colectiva. La consigna "somos el 99\%" en el movimiento Occupy, por ejemplo, expresaba la animadversión por la creciente desigualdad en el planeta atribuida al $1 \%$ de la población mundial, representado por un conjunto de organismos internacionales como el Banco Mundial, el Fondo Monetario Internacional o la Organización del Tratado del Atlántico Norte.

El marco de diagnóstico refiere a la búsqueda de soluciones y de nuevas formas de relacionarse o de ejercer el poder que los actores sociales plantean (Benford y Snow, 2000). Más allá de una lógica racional medios/fines, las aspiraciones utópicas, la apertura de nuevos espacios y la imaginación de nuevos escenarios políticos abren la posibilidad de objetivos, que en una primera instancia podrían ser descalificados por las interpretaciones dominantes. Los pronósticos pueden ser diversos: existen grupos que plantean formas radicales para destruir la dominación capitalista, y otros que no necesariamente procuran destruir el capitalismo, 
sino lograr formas de adaptación con una perspectiva de mayor justicia distributiva, con proyectos socialmente responsables (Della Porta y Diani, 2006: 77).

Finalmente, el marco motivacional y los incentivos que la gente tiene para dar paso a las acciones colectivas resulta fundamental para la comprensión de las acciones colectivas (Benford y Snow, 2000). Ciertamente, existe un cálculo medios/fines en relación con los costos que podría implicar una acción, particularmente en el caso de las acciones contenciosas. Sin embargo, hay elementos que van más allá de dichos cálculos racionales. ¿Qué es lo que hace que una persona decida involucrarse en las acciones colectivas? La solidaridad y las identidades colectivas son referentes importantes para rastrear la motivación de los activistas.

En suma, los marcos de acción colectiva surgidos a partir de las interacciones de los colectivos, junto con las emociones, los sentimientos y los choques morales, son elementos que pueden entenderse como parte del "conocimiento" que orienta las prácticas de los movimientos sociales. La perspectiva cultural adoptada en este estudio ha permitido considerar algunos de estos componentes como constitutivos de la trama de sentidos y significados que se encuentran presentes en los movimientos.

Cabe mencionar que, aunque la teoría del encuadre (frame analysis) ha contribuido a dar un giro en el análisis de los movimientos sociales durante las últimas décadas, ha sido objeto de múltiples críticas, entre las principales: reducir la riqueza de los movimientos sociales, por mostrar una visión demasiado estática de éstos, por basarse en clichés para el estudio de las cuestiones ideológicas vinculadas a los movimientos sociales, por utilizar estos clichés como sinónimos o sustitutos de la ideología, y por omitir consideraciones de carácter emotivo (Jasper, 1997; Benford, 1997; Oliver y Johnston, 2000).

A pesar de estas críticas, sobre las cuales no es posible detenerse en esta comunicación, los marcos y los procesos de encuadre son elementos útiles tanto para el análisis de las estructuras simbólicas que subyacen a las acciones colectivas, como para conocer las estrategias desplegadas para atraer el apoyo de otros actores. En la siguiente parte se examina un conjunto de intervenciones visuales desde la perspectiva de los marcos de acción colectiva, particularmente recuperando los encuadres de diagnóstico y de pronóstico.

\section{Caracterización de la gráfica política (2010-2013)}

En el presente trabajo se analiza una muestra de 63 producciones callejeras, principalmente esténciles ubicados en los primeros cuadros de la ciudad de San Cristóbal de Las Casas, en el llamado "centro histórico".

Las producciones estudiadas fueron organizadas y sistematizadas considerando diferentes tópicos: los personajes, las temáticas y los tiempos/espacios a los que hacían referencia. A partir de estos elementos se obtuvieron frecuencias básicas - evidentemente, sin pretensión de representatividad estadística- La mayoría, el 68.3\% de la muestra, se trató de producciones "mixtas", conformadas por dos elementos lingüísticos, el textual y el icónico; el 23.8\% eran producciones icónicas, conformadas únicamente por imágenes, y el resto, el $7.9 \%$, constaban solamente de texto.

Las producciones "mixtas" ofrecen al espectador una mayor eficiencia comunicativa dado que en ellas coexisten el lenguaje textual y el icónico, de modo que el texto delimita las posibilidades de sentido que genera una imagen, a la vez que esta última fortalece la experiencia visual, ejemplificando una situación concreta.

Las producciones mixtas ofrecen la posibilidad de incluir caracterizaciones de determinados sujetos o personajes. En una producción el personaje puede presentarse como "joven", y al mismo tiempo se revela una silueta "masculina" (ver tablas ly 2). En estos casos, habitualmente el texto termina por dar centralidad a una de estas "identidades", reduciendo el riesgo de sobreinterpretaciones.

Los personajes, por otro lado, pueden interpretarse como actorías sociales: luchadores o luchadoras sociales, indígenas, mujeres, jóvenes, niños, negros o estudiantes, y en otros caos se hace visible el papel de los cuerpos policiacos, que principalmente se muestran 
como antagonistas. Para Jasper (2014), expresiones de este tipo plantean una lógica binaria de "héroes" y "villanos", metáfora que, aunque un tanto reduccionista, revela condiciones de exclusión y dominación.

Por otro lado, se encontraron producciones exclusivamente icónicas. Se trata de la representación de personajes emblemáticos, por lo común sujetos históricos con personalidad identificable (Lizarazo, 2007), como Ernesto Che Guevara, Emiliano Zapata, el subcomandante Marcos, los hermanos Flores Magón, Mahatma Gandhi, Felipe Calderón, Vicente Fox, George W. Bush, Bruce Lee, Cantinflas, Charles Chaplin, Frida Kahlo o Tin-Tan (ver ilustración 3). Aunque la exaltación de unos y la caricaturización de otros sugieren una lectura que nuevamente evoca una distinción entre héroes y villanos, la ausencia de texto permite una libertad mayor en su interpretación, por lo cual se han excluido en este análisis.

En el plano temático se pueden leer, explícita o implícitamente, acciones o acontecimientos referidos a los medios de comunicación - tanto oficiales como independientes-, a la libertad, a la militarización, al capitalismo, al neoliberalismo, a la producción de alimentos, a la violencia, al sistema político hegemónico, a la migración, a las reformas estructurales neoliberales, a la revolución y al graffiti, entre otros. Sin embargo, en las producciones no sólo se plantean estas temáticas generales, sino que además contienen posicionamientos morales.

Después de reconocer los patrones de forma y de contenido en dichas producciones se constató la posibilidad de aventurar un análisis para intentar articular las diferentes unidades de sentido: los personajes -héroes y villanos-, las condiciones sociales y los posicionamientos morales. De manera "natural", surgió una organización de tres tiempos o etapas: el tiempo de las memorias (de deudas históricas), el presente (con condiciones no deseadas) y el futuro (como promesa de lo posible) (ver tabla 3$){ }^{12}$

1. El plano de las memorias permite sostener la existencia de un fuerte cuestionamiento y de denuncia por la falta de democracia, de libertad y de representación efectiva — viejas promesas de las democracias liberales-.

2. En el plano del presente se acumulan diferentes causas de movilización social en los últimos años, tales como el incremento de la violencia, el uso de transgénicos y las reformas estructurales.

3. El plano del futuro remite a la acción, expresada en los siguientes términos: "revolución", "acción directa", "resistencia”, "anticapitalismo", "toma la palabra", "levanta la voz", "recupera la memoria” y "autonomía”; pero también expresa las prácticas de diferentes actores sociales (ver tabla 3).

¿En qué sentido pueden leerse estas discursividades como marcos de acción colectiva? En conjunto, es posible entender la construcción del sentido discursivo de la gráfica analizada como una lectura crítica del pasado, una problematización más concreta del presente, y la proyección hacia futuros deseables y posibles. En suma, puede hablarse de, al menos, dos componentes simbólicos que orientan la acción desde el análisis de los marcos de acción colectiva: los diagnósticos y los pronósticos.

Porotrolado, los significados no puedeninterpretarse de manera aislada. Un lector medianamente enterado puede reconocer que la construcción de los "marcos" expuestos no necesariamente se vincula al plano local; en este sentido, se podría argumentar la vinculación de estas expresiones urbanas con movilizaciones sociales más amplias acontecidas en México durante los últimos años, tales como las movilizaciones por la paz en un contexto de creciente violencia, las manifestaciones en repudio a los feminicidios y las protestas contra las reformas estructurales.

Para ejemplificar el carácter local y nacional de las producciones callejeras se exponen a continuación dos casos particulares: el primero vinculado a la denuncia y el repudio de la violencia de género que existe en las calles de San Cristóbal de Las Casas, situación que se agrava en la vida cotidiana de muchas mujeres jóvenes e indígenas, y, en segundo lugar, la gráfica política realizada por manifestantes en el marco del primer capítulo de las protestas del movimiento magisterial/ 
social contra las reformas estructurales de corte neoliberal en el año 2013.

La creciente violencia que se observa en México es experimentada de manera particularmente intensa por los jóvenes y las mujeres. Los feminicidios reflejan la condición límite de la violencia contra las mujeres, anclada en estructuras patriarcales y en ámbitos de impunidad que definen la condición sacrificial de una parte de la población, cuya vulnerabilidad se construye desde categorías de género, juventud, pobreza, precariedad social, degradación de la justicia y corrupción institucional (Valenzuela, 2012). De acuerdo con cifras proporcionadas por Open Society Foundations (2016), en México se cometieron 4306 feminicidios entre los años 2006 y 2012 (ver ilustración 4).

En San Cristóbal de Las Casas, la violencia de género es un problema cotidiano y en los últimos años la cantidad de feminicidios ha aumentado, lo que ha provocado que diferentes grupos feministas alcen la voz mediante mítines, marchas, foros e intervenciones en los espacios públicos para denunciar estos acontecimientos y exigir justicia. "Ke no te token, ke no te kallen" reza uno de los esténciles en los que se pone de manifiesto la violencia de género. Esta intervención se suma a otras para expresar posicionamientos en defensa de la igualdad, y por el respeto a la diferencia, la dignidad y la libertad humana.

El segundo ejemplo refiere a la primera jornada de protestas organizada por el movimiento magisterial-social en el año 2013. El eje sobre el cual se articuló el conflicto entre el magisterio y el Estado fue la reforma educativa, y "no a la reforma educativa" se convirtió en la consigna central del movimiento. Debido a que esta reforma llegó acompañada por una serie de reformas estructurales, el gremio magisterial se tornó en el centro de un movimiento más amplio al que gradualmente se sumaron organizaciones estudiantiles, campesinas y movimientos populares, de modo que la consigna, entonces, se amplió: "no a las reformas estructurales".

Desde esta primera etapa del movimiento magisterial, la presencia estudiantil fue preponderante en diferentes entidades. En San Cristóbal de Las Casas destacó de forma particular el papel de los estudiantes de educación media-superior y de los normalistas organizados en diferentes frentes (Gómez-Abarca, 2015). El apoyo estudiantil se expresó en la gráfica política, de manera que el 2 de octubre de 2013 no solamente se plasmaron consignas para rememorar la matanza de Tlatelolco, sino también producciones alusivas a las reformas estructurales (ver ilustración 5).

\section{A manera de conclusión}

La interpretación que en este texto se realiza no pretende agotar el sentido de las producciones visuales, sino ofrecer al lector una mirada crítica sobre las mismas e incentivarlo para que realice una interpretación propia. En el proceso de análisis, en primer lugar se dividieron las unidades de sentido en diferentes tópicos $\mathrm{y}$, posteriormente, se organizaron los significados en una línea temporal que hizo patente la construcción de marcos de diagnóstico y pronóstico.

Como toda interpretación, este trabajo está condenado a ser situado e incompleto, pero no por ello es carente de sentido o innecesario. Las motivaciones que impulsan a los actores a participar y a organizarse colectivamente, por ejemplo, no se revelan en las producciones de gráfica política, para lo cual se hace necesario recurrir a otro tipo de fuentes de información. Sin embargo, se puede sostener que un análisis simbólico, con herramientas de tipo semiótico-visual, brinda la posibilidad de comprender una trama de significados que orientan la acción de un conjunto de actores.

Pese a los esfuerzos por acotar la lectura a una espacialidad concreta, las gramáticas militantes continuamente escapan a una interpretación localista y nos llevan a dirigir la mirada hacia otros procesos que operan en escalas espaciales y temporales más amplias. Por lo tanto, una interpretación crítica de las producciones de gráfica política ha implicado el reconocimiento de la histórica desigualdad y exclusión que, en términos sociológicos, continúan enfrentando amplios sectores y grupos de la población mexicana.

Diversos actores, entre los que se encuentran los jóvenes, las mujeres y los indígenas, se pronuncian políticamente desde distintos ámbitos, ampliando y 
pluralizando el espacio de lo político en diferentes lugares. La gráfica política que producen estos actores debe ser entendida como resultado de prácticas sociales y políticas que van más allá de la definición jurídica y estatal, y nos remiten a espacios públicos y políticos conquistados, en los que los ciudadanos colocan los asuntos de interés público, se enuncian los viejos y los nuevos problemas, se demandan soluciones y se plantean alternativas.

Intervenciones como los esténciles, el arte callejero, el arte urbano o el post-graffiti constituyen parte de la experiencia visual urbana contemporánea. Es innegable que una lectura atenta y analítica permite rastrear un universo de significados sociales y políticos, que en algunos casos, como los aquí analizados, pueden definirse como el eco de lo que algunos sectores de la sociedad demandan: justicia, libertad, dignidad, igualdad, paz y democracia, pero también como una acción realizada en el marco de un conjunto de proyectos políticos puestos en marcha.

\section{Notas}

${ }^{1}$ Este trabajo forma parte de una investigación más amplia sobre activismos juveniles desarrollada por el autor entre 2010 y 2016.

${ }^{2}$ Los registros visuales pueden ser consultados en el blog: http://delasvocesurbanas.blogspot.mx/search/label/ esténciles (consultado el 5 de noviembre de 2017).

3 Los esténciles, estarcidos o plantillas refieren una técnica de inscripción muy antigua que, básicamente, se caracteriza por la utilización de pintura que se vierte sobre una plantilla o molde.

${ }^{4} \mathrm{El}$ arte urbano se refiere a un conjunto de intervenciones estéticas en los espacios públicos que incluyen estampas stickers o pegatinas, murales, plantillas, etcétera.

${ }^{5}$ El graffiti-hip-hop es una modalidad que ha tenido mayor centralidad desde las ciencias sociales, por lo cual se conoce gran parte de sus múltiples aristas. Se ha argumentado que, además de ser en muchos casos resultado de actos ilícitos, este tipo de graffiti puede definirse como un acto comunicativo (Sánchez, 2002), un medio sincrético y transcultural (García-Canclini, 2009), una transgresión al ordenamiento social-espacial, lingüístico, político y económico (Valenzuela, 1997), una identidad juvenil (Valenzuela, 2009; Cruz, 2010; Mendoza, 2011), una cultura juvenil (Feixa, 1999; Reguillo, 2000), un discurso gráfico de la disidencia juvenil (Marcial, 2012) o una práctica ciudadana emergente (Reguillo, 2000; Aguilera, 2010).

${ }^{6}$ El postgraffiti, en general, es entendido como sinónimo de arte o urbano, y en términos más precisos refiere al comportamiento artístico no comercial por el cual el artista propaga sin permiso en el espacio público muestras de su producción, utilizando un lenguaje visual inteligible para el público general, y repitiendo un motivo gráfico constante o bien un estilo gráfico reconocible, de forma que el espectador puede percibir cada aparición como parte de un continuo (Abarca, 2010: 385).

${ }^{7}$ Ver: Dávalos (2016).

${ }^{8}$ Incluso, se advierte un papel preponderante de la imagen, expresado en: sus implicaciones en la cultura, sus especificidades, sus complejos procesos de elaboración, y el poder de la misma desplegada a través de diferentes medios.

9 Los fanzines son publicaciones autogestionadas y caracterizadas por ser temáticas, elaboradas con escasos recursos y con poco tiraje, que no necesariamente están involucrados en la lógica comercial.

10 "El gobernador del estado de Chiapas, reconoció hace unos meses, luego de ser denunciado ante el Instituto Federal electoral, haber gastado 130 millones de pesos en comunicación social" (Delgado, 2014).

"En los medios de comunicación hegemónicos usualmente se emiten comentarios negativos sobre los manifestantes descalificando las causas y las acciones de protesta. Con todo esto, se provoca en la construcción de la opinión pública una reducción de las protestas a las acciones de violencia mediatizadas, ocultando las causas y el resto de las acciones colectivas, y justificando así las acciones represivas que se cometan contra éstas. "Vándalos", "radicales", "anarquistas" y "desestabilizadores" fueron algunos de los identificadores negativos utilizados para tales fines.

${ }^{12}$ En este caso, el signo positivo se ha utilizado como símbolo de presencia y el negativo de ausencia. 


\section{Referencias}

Abarca, Francisco (2010). El postgraffiti, su escenario y sus raíces: graffiti, punk, skate y contrapublicidad. Tesis de doctorado, Facultad de Bellas Artes-Universidad Complutense de Madrid.

Aguilera, Óscar (2010). "Cultura política y política de las culturas juveniles". En Utopía y Praxis Latinoamericana. Revista Internacional de Filosofía Iberoamericana y Teoría Social, 15(50), julio-septiembre.

Benedicto, Jorge (1995). “La construcción de los universos políticos de los ciudadanos". En Jorge Benedicto y María de la Luz Moran (eds.), Sociedad y política. Temas de sociología política. Madrid: Alianza.

Benford, Robert (1997). "An insider's Critique of the Social movement framing perspective". En Sociological Inquiry, 67: 409-430.

Benford, Robert y David Snow (2000). "Framing Processes and Social Movements: An Overview and Assessment". En Annual Review of Sociology, 26: 611-639.

Cruz, Tania (2010). "Writers, taggers, graffers y crews. Identidades juveniles en torno al grafiteo". En Nueva Antropología, XXIII(72): 103-120.

Dávalos, Abigail (2016). 'Tú ni siquiera mereces ni un graffiti': el rayado en la dictadura chilena". En Nexos, 7 de junio. Disponible en: www.labrujula.nexos.com. $\mathrm{mx} / \mathrm{p}=835$ (consultado el 16 de octubre de 2017).

Della Porta, Donatella y Mario Diani (2006). Social Movements: An Introduction. Estados Unidos: Blackwell.

Delgado. Álvaro (2014). "Velasco reconoció que gastó 130 millones de pesos en publicidad". En Proceso, 8 de enero.

Feixa, Carles (1999). De jóvenes, bandas y tribus. Antropología de la juventud. Barcelona: Ariel.

García-Canclini, Nestor (2009). Culturas híbridas. Estrategias para entrar y salir de la modernidad. México: Debolsillo.

Gómez-Abarca, Carlos de Jesús (2014). "Graffiti: una expresión político cultural juvenil en San Cristóbal de Las Casas, Chiapas, México". En Revista Latinoamericana de Ciencias Sociales, Niñez y Juventud, 12(2): 675-689.

Gómez-Abarca, Carlos de Jesús (2015). "La participación estudiantil durante las protestas contra las reformas estructurales en México en el año 2013”. En Nuevos métodos para nuevas realidades. México: IMJUVE, Seminario de Investigación en Juventud, Segundo Encuentro Nacional de Jóvenes que Investigan Jóvenes.

González, Gerardo (2007). "Entre el campo y la ciudad. Organismos civiles en San Cristóbal de Las Casas". En Dolores Camacho, Arturo Lomelí y Paulino Hernández (coords.), La ciudad de San Cristóbal de Las Casas: a sus 476 años. Una mirada desde las Ciencias Sociales. Tuxtla Gutiérrez: Consejo Estatal para las Cultura y las Artes de Chiapas.

Jasper, James (1997). The Art of Moral Protest. Chicago: University of Chicago Press.

Jasper, James (2014). Protesto. Uma introdução a os movimentos sociais. Rio de Janeiro: Zahar.

Johnston, Hank (2005). "A Metodology for Frame Analysis. From Discurse to Cognitive Schemata". En Hank Johnston y Bert Klandermans (eds.), Social Movements and Culture. Social Movements, Protest and Contention, t. 4. Minneapolis: University of Minessota Press.

Lazo, Pablo (2007). "La perversión semántica de las imágenes en una sociedad multicultural". En Bolivar Echeverría y Diego Lizarazo (eds.), Sociedades icónicas. Historia, ideología y cultura en la Imagen. México: Siglo XXI.

Lizarazo, Diego (2007). "Encantamiento de la imagen y extravío de la mirada”. En Bolivar Echeverría y Diego Lizarazo (eds.), Sociedades icónicas. Historia, ideología y cultura en la Imagen. México: Siglo XXI.

Marcial, Rogelio (2012). "El graffiti como discurso gráfico de la disidencia juvenil". En Sarah Corona (coord.), Pura imagen. México: Dirección General de Publicaciones del Consejo Nacional Para la Cultura y las Artes.

Melucci, Alberto (1999). Acción colectiva, vida cotidiana y democracia. México: El Colegio de México-Centro de Estudios Sociológicos.

Mendoza, Víctor M. (2011). "Graffiti: construcción identitaria juvenil en la ciudad de México". Tesis de licenciatura, Universidad Nacional Autónoma de México, Ciudad de México. 
Morales Vargas, María de Lourdes (2013). "El esténcil políticoen San Cristóbalde Las Casas. Una metáforadel discurso". En Anuario 2012 del Centro de Estudios Superiores de México y Centroamérica. Tuxtla Gutiérrez: Centro de Estudios Superiores de México y CentroaméricaUniversidad de Ciencias y Artes de Chiapas.

Oliver, Pamela y Hank Johnston (2000). "What a Good Idea! Frames and Ideologies in Social Movement Research". En Mobilization: An International Quarterly, 5(1): 37-54.

Open Society Foundations (2016). "Confrontando crímenes de lesa humanidad en México". Disponible en: www. opensocietyfoundations.org/reports/undeniableatrocities-confronting-crimes-against-humanity-mexico/ es (consultado el 2 de septiembre de 2017).

Reguillo, Rossana (2000). Emergencias de culturas juveniles. Estrategias del desencanto. Bogotá: Norma.

Rodríguez, Marvin (2016). Enlacalleymásallá:unaaproximación sociológica al arte graffiti. Costa Rica: Arlequín.

Rus, Jan (2009). "La nueva ciudad maya en el valle de Jovel: urbanización acelerada, juventud indígena y comunidad en San Cristóbal de Las Casas". En Marco Estrada (ed.), Chiapas después de la tormenta. Estudios sobre economía, sociedad y política. México: El Colegio de México, Gobierno del Estado de Chiapas, Cámara de Diputados LX Legislatura.

Rus,Jan(2012). Elocasodelasfincasylatransformacióndela sociedad indigena de Los Altos de Chiapas. Tuxtla Gutiérrez: Centro de Estudios Superiores de México y CentroaméricaUniversidad de Ciencias y Artes de Chiapas.
Sánchez, Alfredo (2002). "La pigmentación del sueño urbano a través del graffiti”. En Alfredo Nateras (ed.), Jóvenes, cultura e identidades urbanas. México: Miguel Ángel Porrúa, UAM, pp. 171-185.

Sartori, Giovanni (1998). Homo Videns. La sociedad teledirigida. México: Taurus.

Snow, David, Rochford, E. Burke, Worden, Esteven y Benford, Robert (1986). "Frame Alignment Processes, Micromobilization, and Movement Participation". En American Sociological Review, 51(4): 464-481.

Ulrich, Peter, Priska Daphi y Britta Baumgarten (2014). "Protest and Culture: Concepts and Appproaches in Social Movement Research. An Introduction". En Britta Baumgarten, Priska Daphi y Peter Ulrich (eds.), Conceptualizing Culture in Social Movement Research. Nueva York: Palgrave MacMillan.

Valenzuela, José M. (1997). Vida de barro duro: Cultura popular juvenil y graffiti. Guadalajara, Jalisco y Tijuana: Universidad de Guadalajara, El Colegio de la Frontera Norte.

Valenzuela, José M. (2009). Elfuturoya fue. Socioantropología de l@s jóvenes en la modernidad. México: El Colegio de la Frontera Norte.

Valenzuela, José M. (2012). Sed de mal. Feminicidio, jóvenes y exclusión social. México: El Colegio de la Frontera Norte, Universidad Autónoma de Nuevo León.

Viqueira, Juan P. (2002). Encrucijadas chiapanecas: economía, religión e identidades. México: El Colegio de MéxicoCentro de Estudios Históricos, Tusquets Editores. 
Ilustración 1. Realización de esténcil durante manifestación

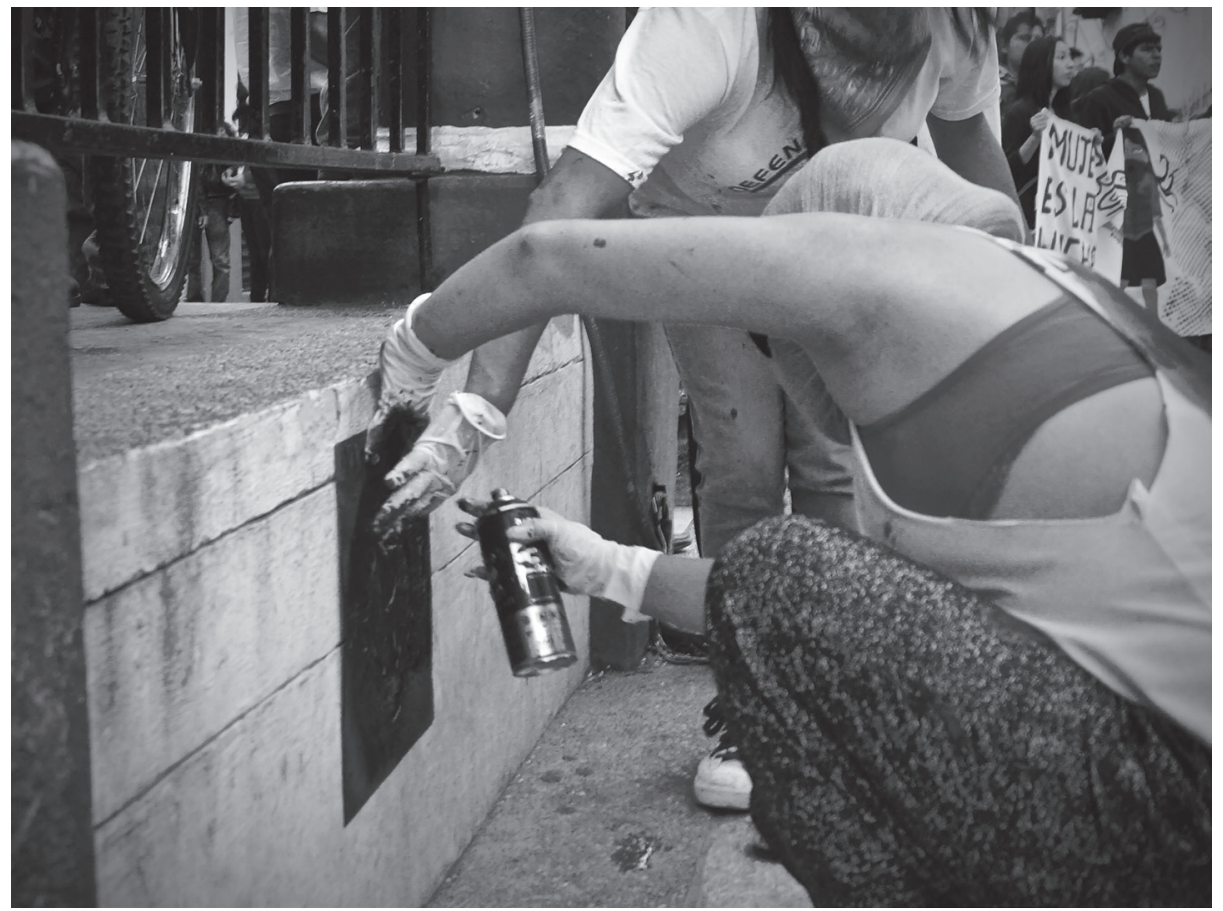

Fuente: archivo personal.

Ilustración 2. Propaganda política institucional del gobernador del estado de Chiapas (2014)
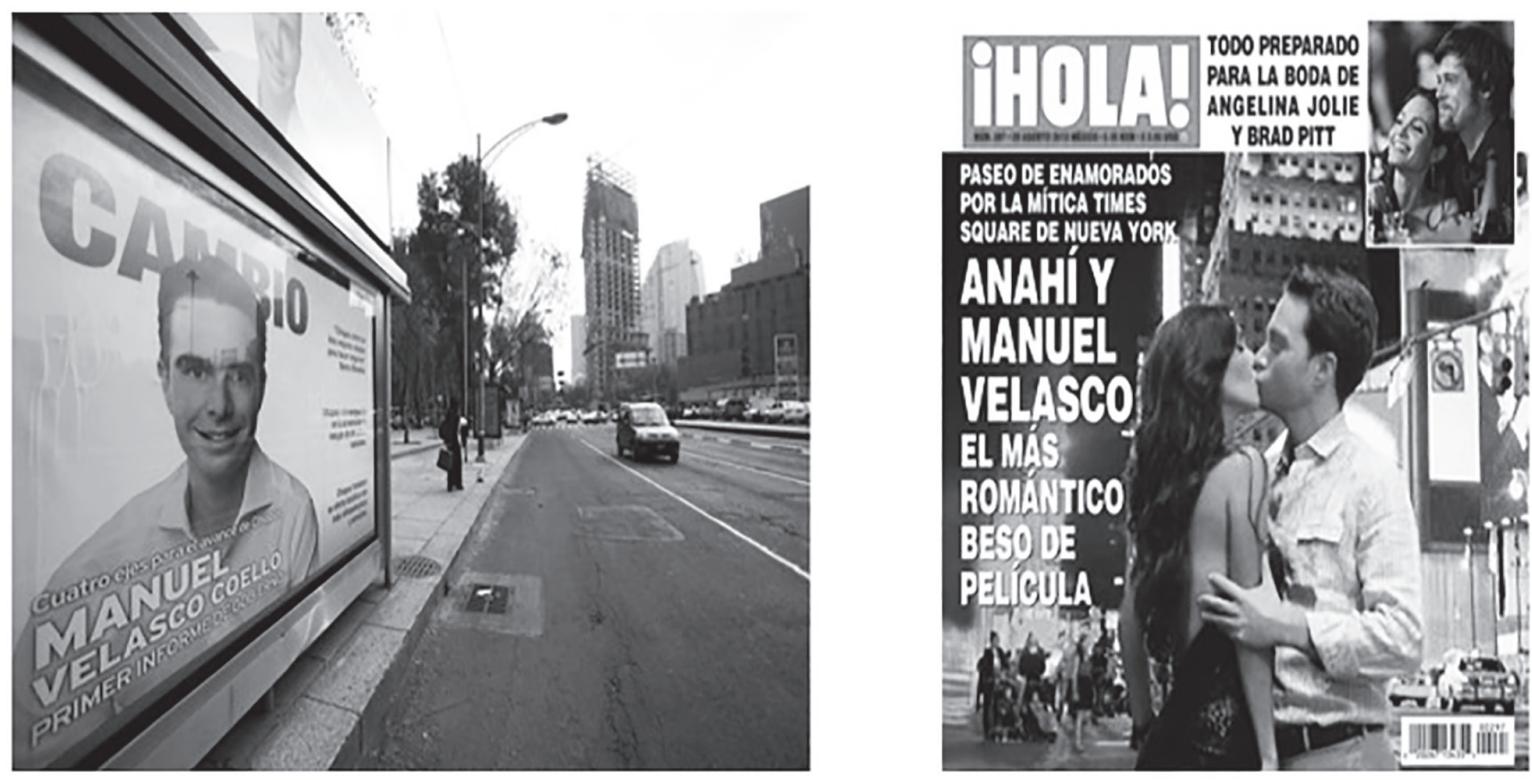

Fuente: elaboración propia con base en imágenes, sin autor, que circulan por Internet. 
Ilustración 3. Intervenciones icónicas
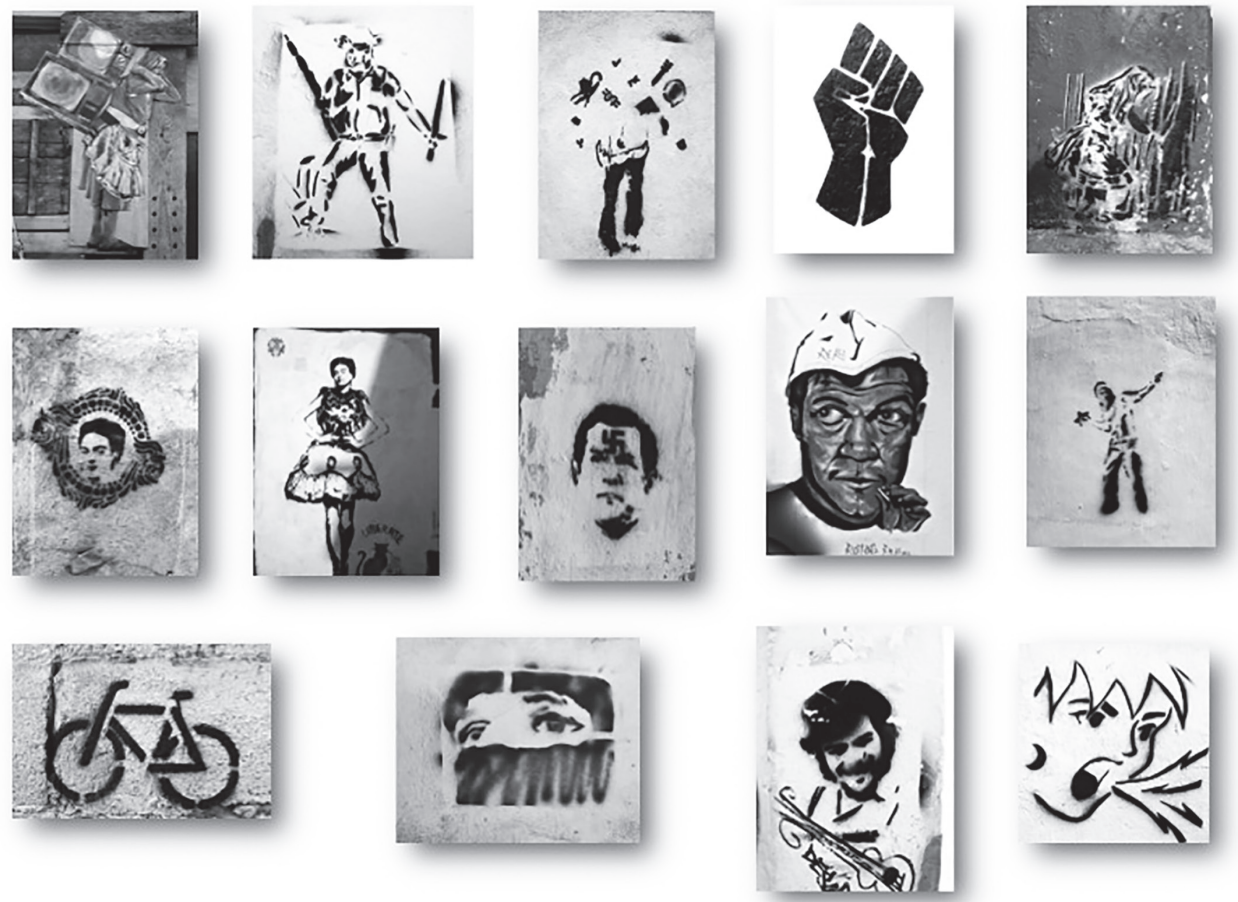

Fuente: archivo personal.

Ilustración 4. Intervenciones en las que se cuestiona la violencia patriarcal

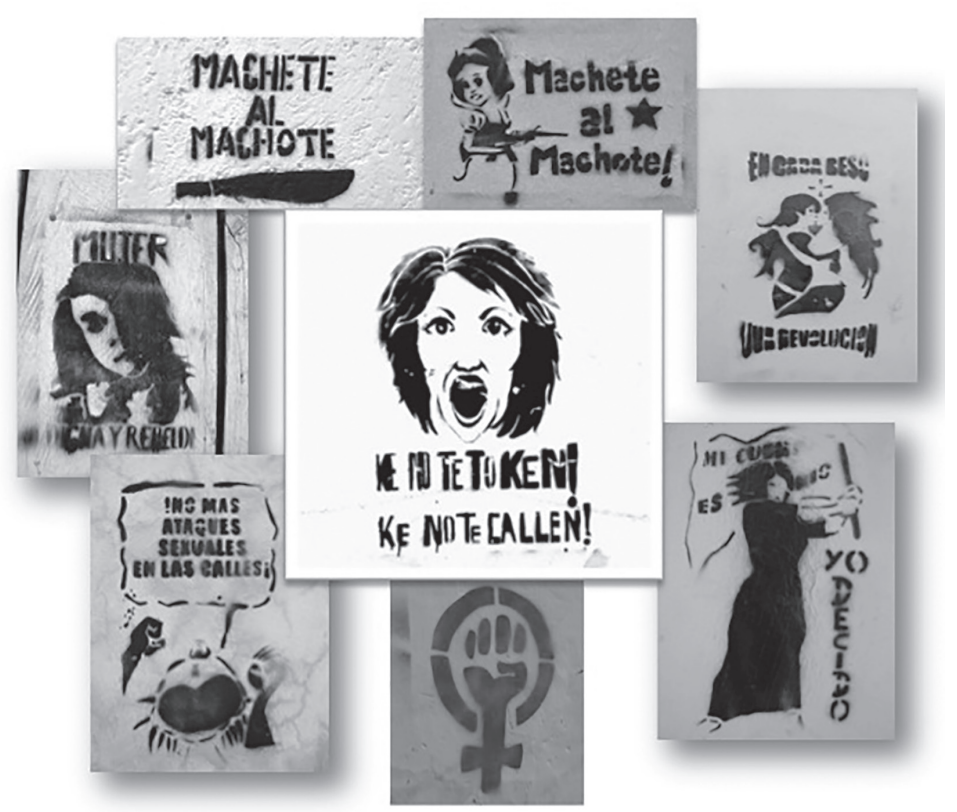

Fuente: archivo personal. 
Ilustración 5. Gráfica política realizada el 2 de octubre de 2013

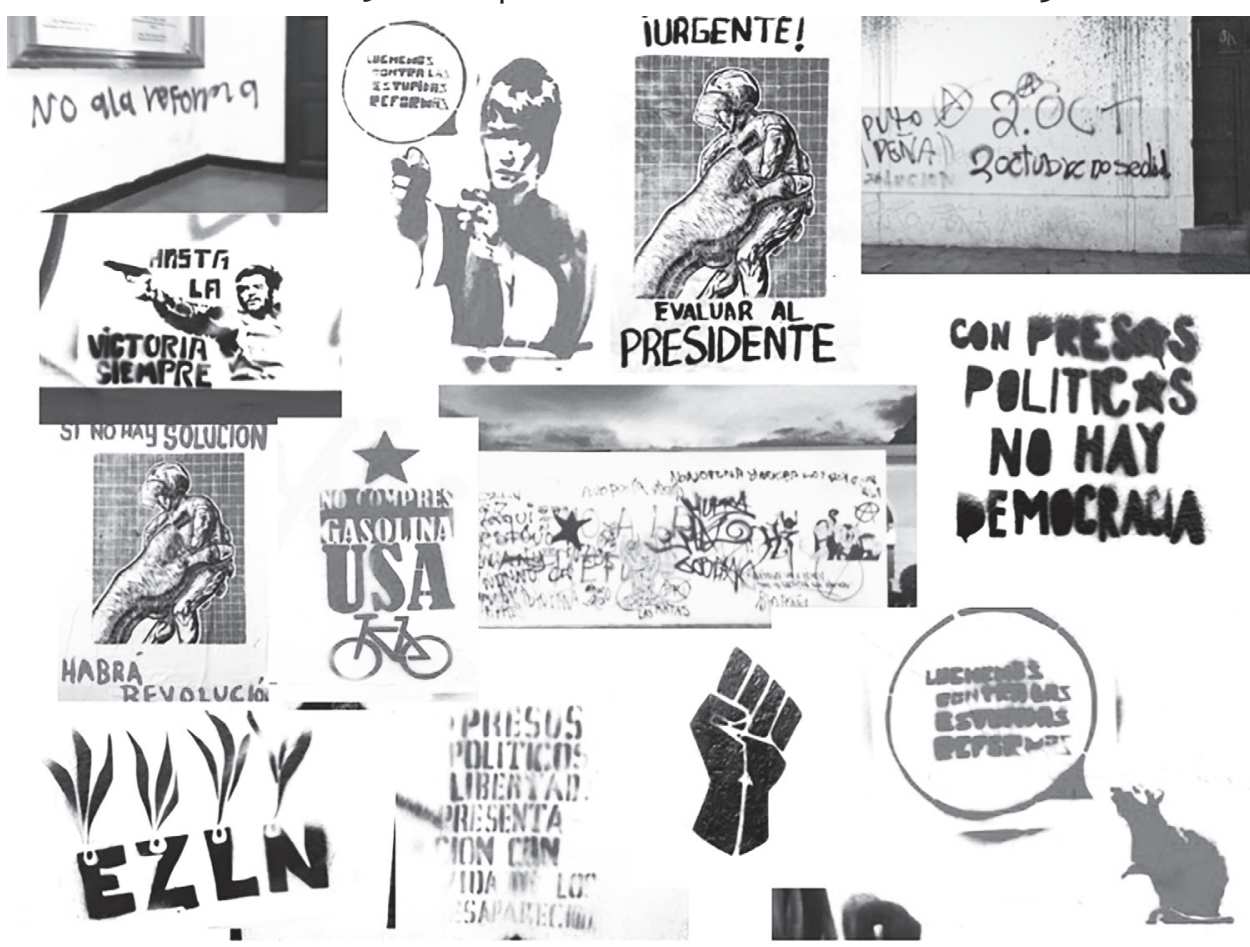

Fuente: archivo personal.

Tabla 1. Frecuencias de personajes sugeridos en la gráfica política

\begin{tabular}{lcc}
\hline \multicolumn{1}{c}{ Personaje 1 } & Número de casos & $\begin{array}{c}\text { Porcentaje con } \\
\text { respecto al total }\end{array}$ \\
\hline Joven & 4 & 6.3 \\
Mujer & 10 & 15.9 \\
Persona & 10 & 15.9 \\
Infancia & 1 & 1.6 \\
Policía/militar & 3 & 4.8 \\
Militante & 9 & 14.3 \\
Indígena & 2 & 3.2 \\
Total de personajes & 39 & 61.9 \\
No aplica & 24 & 38.1 \\
\hline Total de casos & 63 & 100 \\
\hline
\end{tabular}

Fuente: elaboración propia. 
Tabla 2. Frecuencias de segundos personajes sugeridos en (algunas) producciones de gráfica política

\begin{tabular}{lcc}
\hline \multicolumn{1}{c}{ Personaje 2 } & Número de casos & $\begin{array}{c}\text { Porcentaje con respecto } \\
\text { al total }\end{array}$ \\
\hline Joven & 1 & 1.6 \\
Mujer & 1 & 1.6 \\
Militante & 2 & 3.2 \\
Indígena & 1 & 1.6 \\
Afrodescendiente & 1 & 1.6 \\
Estudiante & 3 & 4.8 \\
Total de personajes 2 & 9 & 14.3 \\
No aplica & 54 & 85.7 \\
\hline Total de casos & 63 & 100 \\
\hline
\end{tabular}

Fuente: elaboración propia.

Tabla 3. Tres planos temporales sugeridos en la gráfica política

\begin{tabular}{lll}
\hline \multicolumn{1}{c}{ La memoria } & \multicolumn{1}{c}{ El presente } & \multicolumn{1}{c}{ El futuro } \\
\hline & & + Resistencias \\
- Democracia & + Violencia & + Anticapitalismo \\
- Libertad & + Transgénicos & + Autonomía \\
- Representación efectiva & + Liderazgos innecesarios & + Acción directa \\
- Dignidad & + Reformas neoliberales & + Alza la voz \\
& + Olvido & + Liberación \\
& & + Revolución \\
& & + Memoria \\
\hline
\end{tabular}

Fuente: elaboración propia. 